\title{
Physically-sound simulation of low-velocity impact on fiber reinforced laminates
}

\author{
C.S. Lopes ，S. Sádaba ,C. González ， J. Llorca ，P.P. Camanho
}

\begin{abstract}
A B S T R A C T
A high-fidelity virtual tool for the numerical simulation of low-velocity impact damage in unidirectional composite laminates is proposed. A continuum material model for the simulation of intraply damage phenomena is implemented in a numerical scheme as a user subroutine of the commercially available Abaqus finite element package. Delaminations are simulated using of cohesive surfaces. The use of structured meshes, aligned with fiber directions allows the physically-sound simulation of matrix cracks parallel to fiber directions, and their interaction with the development of delaminations. The implementation of element erosion criteria and the application of intraply and interlaminar friction allow for the simulation of fiber splits and their entanglement, which in turn results in permanent indentation in the impacted laminate. It is shown that this simulation strategy gives sound results for impact energies bellow and above the Barely Visible Impact Damage threshold, up to laminate perforation conditions.
\end{abstract}

\section{Introduction}

Low-velocity impact (LVI) events occur with some frequency on composite structures such as airplane components. From ground operations to unavoidable birds, there is a range of situations where an external aircraft component may be subjected to unexpected impact loads. In most cases, such as tool dropping, the impactor has a relatively high mass and a low velocity. The damage produced may be barely visible from the outside of the laminate, in the form of a small indentation, while the inside may hide delaminations that are not easily detectable through routine inspections. The spread of these delaminations over wide areas of the structure may severely compromise its residual compressive strength. Therefore, the ability to predict the impact damage resulting from potential LVI events is of great importance in the aeronautical industry.

Traditionally, impact damage models rely on either analytical calculations or extensive experimental data. On one side, analytical predictions of the impact damage resistance and tolerance of composite laminates are overly simplified and unreliable. Several authors have proposed analytical formulations for the prediction of impact damage in composite laminates [1,2]. However, the complexity of the physical phenomena, which includes dynamic structural be- havior and loading, contact, friction, damage and failure, often results in an oversimplification of the problem and limits the analytical models. Conversely, testing each promising design is time-consuming and costly. Low-cost virtual testing, by means of nonlinear finite element (FE) analyses, could replace most of the actual impact testing of laminates. The numerical approach is a more flexible and powerful alternative to analytical formulations. The possibility of modeling the constitutive behavior of each material at local (element) level adds to the capacity of simulation of complex structures under seemingly complex external loads and boundary conditions.

In the present work, a reliable numerical strategy for the simulation of impact damage in composite laminates at the mesostructural level is proposed. Under out-of-plane loads, such as impact, laminated composites may suffer damage in the form of different mechanisms such as: (i) matrix cracking and fiber failure and (ii) delaminations at interfaces between plies. If acceptable accuracy is to be expected from the numerical impact analyses, these damage phenomena need to be well captured.

Continuum damage mechanics (CDM) is an accurate framework to predict the quasi-brittle process of failure in composites, where the gradual unloading of a ply after the onset of damage is simulated by means of a material degradation model. Non-linear constitutive models defined in the context of the mechanics of continuum media have been developed and implemented in FE codes in the past [3]. The damage model used in this work is an extension to three-dimensional scenarios of the plane stress formulation proposed by Maimí et al. [4,5] for in-plane behavior. The main 
advantages of this formulation are: (i) the use of the physicallybased LaRC04 failure criteria [6] for the prediction of the onset of matrix cracking and fiber fracture under tensile and compressive loads; (ii) the accounting for the effects of thickness and constraining on the apparent ply transverse tensile and shear strengths [7]; (iii) the modification of Bažants crack band model [8,9] to ensure a mesh-independent solution in scenarios where the fracture planes may have several orientations, and (iv) the simulation of crackclosure effects under load reversal cycles. Nevertheless, the application of this model is limited to the range of quasi-static loading and low strain-rate conditions, which encompass LVI events [1].

Additionally, information from the material damage mechanics at microstructural level is passed to the meso-structural level, namely the model kinematics drive matrix cracks to progress parallel to fiber directions. The importance of the correct prediction of matrix cracking in impact situations has been previously identified by some authors $[10,11]$ who adopted the modeling technique consisting of introducing patterns of cohesive intralaminar cracks that open according to a cohesive fracture criterion. The drawbacks of this approach are the added model preprocessing difficulties and the possible influence of the cohesive penalty stiffness on the global stiffness of the impacted specimen. A different strategy was adopted by Laš and Zemčík [12] who took advantage of the preferential crack alignment with mesh lines of the intralaminar CDM model. However, the ply-to-ply stacking sequence was limited by mesh constraints. Previous simulations using conforming meshes [13-16] have shown the limitations of this strategy in the correct prediction of matrix cracking directionality, a characteristic that strongly interferes with other damage mechanisms such as delamination and perforation.

In this work, several modeling techniques are explored in an effort to correctly capture the impact phenomenology, in particular the relevant damage mechanisms. The influence of material-aligned and non-aligned meshes on the LVI response is studied, as well as the influence of using cohesive elements or cohesive contacting surfaces. In the case of cohesive elements, a stabilization technique is explored to avoid sharp, non-physical oscillations during crack opening. The study converges in that the most accurate methodology is as follows. Each laminate ply is modeled using a single layer of reduce-integration brick elements associated with the constitutive model presented below. The interfaces between the plies are simulated by means of traction-separation cohesive behavior, and post-decohesion friction, coupled with a surface contact algorithm [17]. This constitutes a reliable numerical tool for the prediction of delamination under several loading scenarios, and allows for non-conforming meshes between delaminating plies. These are generated by aligning the mesh on each ply with fiber directions in order to correctly simulate matrix cracking. Element erosion and the application of friction allow the simulation of fiber splits and their entanglement which results in the permanent indentation of the impacted specimen.

A brief description of the material models used in this work is given in Section 2. In Section 3, several techniques for impact modeling are explored, and their advantages and disadvantages are identified. In Section 4, the most suitable technique is applied to the practical simulation of the standard drop-weight impact test [18]. Finally, conclusions of this work are presented in Section 5.

\section{Continuum models for impact damage}

Two distinct formulations are used to simulate the damage phenomena occurring in layered composites under out-of-plane, lowvelocity impact loading: (i) a continuum damage model, to address the matrix and fiber damage occurring at ply level and (ii) a cohesive damage model to account for delamination. While in the case of delamination, the crack plane is known a priori, the location and direction of matrix cracks and fiber breakage bands needs to be determined along with the analysis.

The intraply damage model used in this work follows the formulation developed and implemented by Maimí et al. [4,5] for inplane stress analysis with implicit integration of the equilibrium equations. In the present case, the original formulation was extended to take into account stress states in the three-dimensional stress space and was implemented for the explicit integration method, namely it was coded as an Abaqus/Explicit VUMAT userwritten subroutine [17]. The cohesive damage model is based on the explicit implementation in cohesive elements [19] and cohesive contacting surfaces [17] of the formulation initially proposed by Camanho et al. [20]. The main aspects of these models are presented in the following.

\subsection{Continuum damage model for a 3D ply}

For each damage mode, the ply constitutive model used in this work follows the general form schematically represented in Fig. 1a. The material response is linear-elastic until the onset of damage and, at higher strains, it softens according to an exponential law.

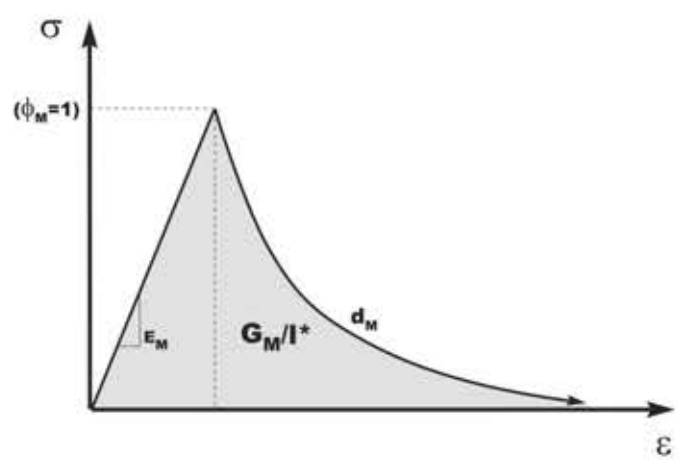

(a)

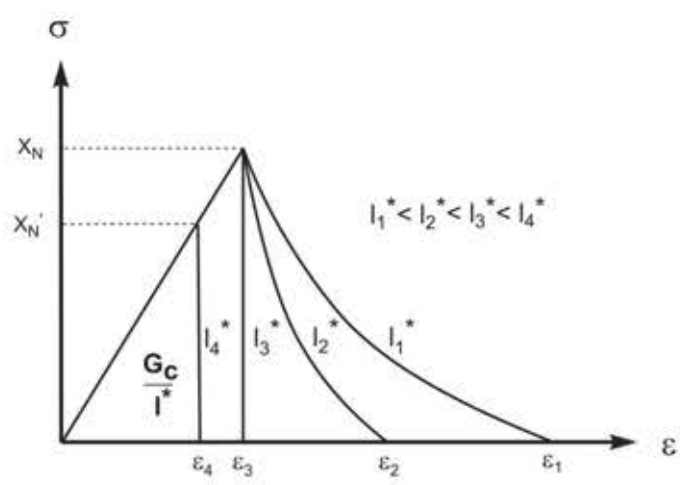

(b)

Fig. 1. Typical nominal stress-strain behavior for each material direction and illustration of the strategy used by the intraply damage model [4,5] to account for different element sizes. 
The proposed complementary free energy density of a transversely isotropic ply $\left(E_{2}=E_{3}, G_{12}=G_{13}\right.$, and $\left.v_{12}=v_{13}\right)$ is defined as:

$$
\begin{aligned}
G= & \frac{\sigma_{11}^{2}}{2\left(1-d_{1}\right) E_{1}}+\frac{1}{2 E_{2}}\left[\frac{\sigma_{22}^{2}}{\left(1-d_{2}\right)}+\frac{\sigma_{33}^{2}}{\left(1-d_{3}\right)}\right]-\frac{v_{12}}{E_{1}}\left(\sigma_{22}+\sigma_{33}\right) \sigma_{11} \\
& -\frac{v_{23}}{E_{2}} \sigma_{22} \sigma_{33}+\frac{\sigma_{12}^{2}}{2\left(1-d_{6}\right) G_{12}}+\frac{\sigma_{12}^{2}}{2\left(1-d_{5}\right) G_{12}}+\frac{\sigma_{23}^{2}}{2\left(1-d_{4}\right) G_{23}} \\
& +\left[\alpha_{11} \sigma_{11}+\alpha_{22}\left(\sigma_{22}+\sigma_{33}\right)\right] \Delta T+\left[\beta_{11} \sigma_{11}+\beta_{22}\left(\sigma_{22}+\sigma_{33}\right)\right] \Delta M
\end{aligned}
$$

where $d_{1}$ is the damage variable associated with longitudinal (fiber) failure. Transverse matrix cracking is controlled by $d_{2}$, for inplane loads, and by $d_{3}$ for out-of-plane loads. The damage variables $d_{4}, d_{5}$ and $d_{6}$ are influenced by longitudinal and transverse cracks. $\alpha_{i i}$ and $\beta_{i i},(i=1,2)$ are, respectively, the coefficients of thermal and hygroscopic expansion in the longitudinal $(i=1)$ and transverse directions $(i=2)$. The temperature and moisture content variations with respect to the corresponding reference values are expressed as $\Delta T$ and $\Delta M$, respectively.

The strain tensor, $\varepsilon=\left\{\varepsilon_{11}, \varepsilon_{22}, \varepsilon_{33}, \gamma_{12}, \gamma_{13}, \gamma_{23}\right\}^{T}$, results from the differentiation of the complementary free energy density with respect to the stress tensor, $\sigma=\left\{\sigma_{11}, \sigma_{22}, \sigma_{33}, \sigma_{12}, \sigma_{13}, \sigma_{23}\right\}^{\top}$ :

$\varepsilon=\frac{\partial G}{\partial \sigma}=\mathbf{H}: \sigma+\alpha \Delta T+\beta \Delta M$

Here, $\mathbf{H}$ is the lamina compliance tensor represented as:

\subsubsection{Damage activation functions}

The elastic domain is assumed to be bounded by four distinct damage activation functions based on the LaRCO4 failure criteria [6]: longitudinal and transverse fracture under tension and compression. The four damage activation functions, $F_{N}$, associated with damage in the longitudinal $\left(N=1+, 1^{-}\right)$and transverse $(N=2+, 2-)$ directions are defined as:

$F_{1+}=\phi_{1+}-r_{1+} \leq 0 ; F_{1-}=\phi_{1-}-r_{1-} \leq 0$
$F_{2+}=\phi_{2+}-r_{2+} \leq 0 ; F_{2-}=\phi_{2-}-r_{2-} \leq 0$

where the loading functions $\phi_{N}(N=1+, 1-, 2+, 2-)$ depend on the strain tensor and on the material constants (elastic and strength properties). The explicit form of these functions and their implementation in the damage model is described in Refs. [4,5]. The elastic domain thresholds $r_{N}(N=1+, 1-, 2+, 2-)$ are related to the damage variables $d_{M}(M=1+, 1-, 2+, 2-, 6)$ by the damage evolution laws. The damage variables take the value of zero for an undamaged material and increase with damage evolution up to unity, corresponding to final failure.

\subsubsection{Damage evolution laws}

The exponential damage evolution laws proposed by Maimi et al. $[4,5]$ are expressed in the following general form:

$d_{M}=1-\frac{1}{f_{N}\left(r_{N}\right)} \exp \left\{A_{M}\left[1-f_{N}\left(r_{N}\right)\right]\right\} f\left(r_{K}\right)$

$$
\mathbf{H}=\frac{\partial^{2} G}{\partial \sigma \otimes \partial \sigma}=\left[\begin{array}{cccccc}
\frac{1}{\left(1-d_{1}\right) E_{1}} & -\frac{v_{12}}{E_{1}} & -\frac{v_{12}}{E_{1}} & 0 & 0 & 0 \\
-\frac{v_{12}}{E_{1}} & \frac{1}{\left(1-d_{2}\right) E_{2}} & -\frac{v_{23}}{E_{2}} & 0 & 0 & 0 \\
-\frac{v_{12}}{E_{1}} & -\frac{v_{23}}{E_{2}} & \frac{1}{\left(1-d_{3}\right) E_{2}} & 0 & 0 & 0 \\
0 & 0 & 0 & \frac{1}{\left(1-d_{6}\right) G_{12}} & 0 & 0 \\
0 & 0 & 0 & 0 & \frac{1}{\left(1-d_{5}\right) G_{12}} & 0 \\
0 & 0 & 0 & 0 & 0 & \frac{1}{\left(1-d_{4}\right) G_{23}}
\end{array}\right]
$$

where the function $f_{N}\left(r_{N}\right)$ is selected to force the softening of the constitutive relation and $f\left(r_{k}\right)$ is the coupling factor between damage laws and elastic threshold domains. The damage law parameters $A_{M}(M=1+, 1-, 2+, 2-, 6)$ are calculated internally by means of numerical integration to ensure that the computed dissipated energy is independent of mesh refinement [21]. The damage evolution laws for each damage variable are described in detail by Maimí et al. [4,5].

\subsubsection{Mesh regularization}

The continuum damage formulation used in this work models the damage mechanisms occurring at spatially-discrete locations, as if they are smeared over the finite size of the elements. A zerothickness mesocrack is simulated by the failure of a single band of solid elements. With crack progression, the crack energy release rate $(\mathcal{G})$ must be properly computed by the numerical model.

The standard implementation of strain-softening constitutive models leads to mesh-dependent results, i.e. the solution is nonobjective with respect to the mesh refinement, and the computed energy dissipated decreases with the reduction in the element size. An effective technique to assure objective solutions involves using 
the element characteristic length, $1^{*}$, in a mesh regularization scheme, as proposed by Bažant $[8,9]$ and explained bellow. However, there is a maximum size of a finite element that ensures that the energy release rate is correctly computed. If an element is too large, its own elastic energy per unit area is higher than the material fracture toughness and the model will over-predict the energy dissipation.

The damage model overcomes this problem by reducing the strength of the material associated with such an element while maintaining its fracture toughness constant, as illustrated in Fig. 1b. This is acceptable in models wherein the prediction of damage initiation is of secondary importance as compared to the simulation of the global behavior, or the determination of final failure loads. In the case of impact simulations, one of the main goals is the determination of the impact load that triggers the initiation of damage because this will strongly influence the following chain of events. Therefore, in the region of impact, the elements should be small enough to guarantee the correct representation of both material strength and fracture toughness. For each damage mode $M$, the elastic energy of these elements at the onset of failure, $\frac{1}{2} \frac{X_{M}^{2}}{E_{M}}\left(l^{*}\right)^{2} h_{p}$, should not be higher than the energy dissipated during the fracture process $[4,5], \mathcal{G}_{\mathrm{M}} l^{*} h_{p}$, i.e.

$l^{*} \leq \frac{2 E_{M} \mathcal{G}_{M}}{X_{M}^{2}}, M=1 \pm, 2 \pm, 6$

wherein $E_{M}, \mathcal{G}_{M}$ and $X_{M}$ are, respectively, the Young modulii, fracture toughness and ply strengths corresponding to each failure mode ( $h_{p}$ is the ply thickness). For an in-plane isotropic mesh, $l^{*}$ is the square root of the area represented by one integration point. In Section 4, further consideration is given to the characteristic length, mesh directionality and element aspect ratio.

\subsubsection{Model input properties}

The following independent ply material properties are needed as input data of the continuum damage model:

- Ply elastic properties $\left(E_{1}, E_{2}, G_{12}, G_{23}, v_{12}, v_{23}\right)$ and ply strengths $\left(X_{T}, X_{C}, Y_{T}, Y_{C}, S_{L}\right)$. These properties can be measured using test standards defined by the American Society for Testing and Material Standards (ASTM) [22-24] or predicted by means of computational micromechanics in the framework of a multiscale modeling of composites approach $[25,26]$.

- Four components of the fracture toughness, associated with longitudinal failure in tension and compression ( $\mathcal{G}_{1+}$ and $\mathcal{G}_{1-}$, respectively) and with transverse failure in tension and shear ( $\mathcal{G}_{2+}$ and $\mathcal{G}_{6}$, respectively). $\mathcal{G}_{2+}$ can be measured using a standard test procedure devised by the ASTM [27]. $\mathcal{G}_{1+}$ and $\mathcal{G}_{1-}$ are measured using non-standard tests developed either by Pinho et al. [28] or by Catalanotti et al. [29,30]. $\mathcal{G}_{6}$ can be measured using the four-point bending end-notched flexure test proposed by Martin et al. [31].

The fracture toughness $\mathcal{G}_{2}$ is dependent on $\mathcal{G}_{6}$ and on the fracture angle $\alpha_{0}$ in the form $\mathcal{G}_{2-}=\mathcal{G}_{6} / \cos \left(\alpha_{0}\right)[4,5]$. Additionally, the model requires the input of the in-situ strengths $Y_{T}^{i s}$ and $S_{L}^{i s}$, which are functions of the independent material properties [7].

\subsection{Cohesive zone damage model for zero- and finite-thickness interfaces}

The bond between each layer is simulated by means of the cohesive zone approach proposed by Camanho et al. [20]. Using this strategy, there are two alternatives to model the fracture behavior (delamination) of the bond between each layer: a) lumped into a very thin cohesive layer representing the resin-rich region between each two consecutive layers. These regions are simulated by means of a layer of explicitly-integrated cohesive elements placed between each ply [19], as shown in Fig. 2a; or b) by means of a cohesive zone surface behavior coupled with a penalty surface contact algorithm [17]. In the later approach, the fracture behavior (delamination) is lumped into a zero-thickness cohesive region. In both alternatives, the relative displacement of the two surfaces attached to the adjacent continuum elements that model the layers is a measure of the opening of the delamination crack. The opening is controlled by means of a bilinear cohesive constitutive relation, shown in Fig. 2b, that defines the delamination process.

\subsubsection{Model input properties}

The independent material properties required to completely define the cohesive model are:

- Elastic properties of the interface material, $E_{m}$ and $v_{m}$. These can be approximated using the ply material properties as $E_{m} \approx E_{2}$ and $v_{m} \approx v_{23}$.

- Interface strengths for pure mode $\mathrm{I}$ and shear modes (II and III), $\tau_{3}^{0}$ and $\tau_{1}^{0}$, which can be approximated as $\tau_{3}^{0} \approx Y^{\top}$ and $\tau_{1}^{0} \approx S^{L}$.

- Interfacial fracture toughness for pure mode I and shear modes (II and III), $\mathcal{G}_{\text {lc }}=\mathcal{G}_{2+}$ and $\mathcal{G}_{\text {IIc }}=\mathcal{G}_{6}$.

- The mode interaction parameter $\eta$, determined by exponential interpolation of the interlaminar fracture toughness values obtained experimentally for a few discrete mixed-mode ratios, e.g. $\frac{G_{l}}{G_{T}}=0,0.25,0.5,0.75,1$, as proposed by Camanho et al. [20].

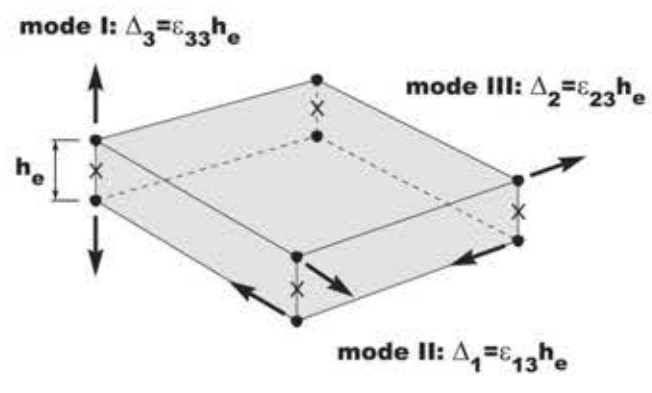

(a) Finite thickness cohesive element

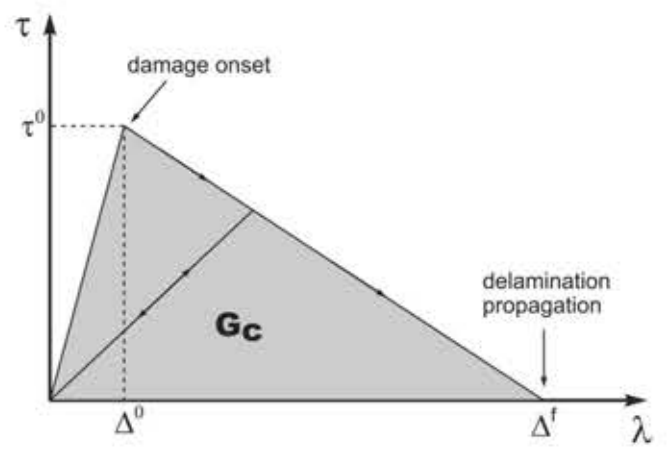

(b) Bilinear constitutive equation

Fig. 2. Parameters of the cohesive element formulation in an explicit FE code. 
Therefore, except for the parameter $\eta$, the material properties required for the definition of the cohesive model are common to the ones required to define the intraply damage model. In order to define the parameter $\eta$, the Mixed-Mode Bending (MMB) test, as proposed by Crews and Reeder [32], needs to be carried out.

\section{Techniques for the simulation of Low Velocity Impact on FRP}

In this section, several modeling techniques are explored for the high-fidelity simulation of low-velocity impact on FRP by means of the CDM models introduced above. An experimental campaign was performed with CFRP laminated specimens using the dropweight impact test, a standard procedure to characterize the impact behavior of materials at low velocity. Two of those tests were selected to analyze the damage process in detail.

\subsection{Experimental set-up and test results}

Low velocity impact tests were performed with a drop-weight testing machine equipped with a carriage fitted with interchangeable metal plates (4.98 and $11.72 \mathrm{~kg}$ ) and an adjustable drop height. The impactor had a hemispherical tip $(D=12.7 \mathrm{~mm}$ ) instrumented with an accelerometer. By time integration, both the velocity and displacement can be obtained, while the impact force is given by the acceleration and the mass.

The material used in this study was a carbon/epoxy unidirectional system, with $60 \%$ fiber volume fraction, consolidated in autoclave at $180{ }^{\circ} \mathrm{C}$, whose properties were obtained by the methodology described above. The 32-ply specimens were laminated with the stacking sequence $[45 /-45 /-45 / 45 / 90 / 90 / 0 / 90 / 90 / 45 /-45 /-45 / 45 / 90 / 90 / 0]_{S}$ resulting in a nominal thickness of $5.88 \mathrm{~mm}$ ( $h_{p}=0.125 \mathrm{~mm}$ ).

Specimens with dimensions of $145 \times 145 \mathrm{~mm}^{2}$ were clamped by their corners on a frame with a square window of $127 \times 127 \mathrm{~mm}^{2}$ to allow the deflection of the impacted zone. All tests were carried out at approximately $4 \mathrm{~m} / \mathrm{s}$ and the impact energy was varied from $42 \mathrm{~J}$ to $240 \mathrm{~J}$. The impacted specimens were then inspected by ultrasound C-scan in a water tank. For a better insight on the impact damage, a $20 \mathrm{~mm}$ strip was cut from one of the impacted specimens, encompassing the damaged zone, and scanned by X-ray Computed Tomography (CT).

The load-displacement curves for the tests at $42 \mathrm{~J}, 94 \mathrm{~J}$ and $150 \mathrm{~J}$ are shown in Figure reffig:drop-curves-32. The specimens impacted at $42 \mathrm{~J}$ and $94 \mathrm{~J}$ were selected as case studies for detailed inspection since they represent distinct stages of damage with varying impact energy. The specimen impacted at $42 \mathrm{~J}$ exhibits mostly delamination damage while the for the $94 \mathrm{~J}$ case, partial perforation is visible (see Fig. 3).

\subsection{Virtual testing set-up}

The drop-weight impact test was simulated using Abaqus/ Explicit [17]. The model, shown in Fig. 4, is constituted by: a deformable (composite specimen) domain of $145 \times 145 \mathrm{~mm}^{2}$; a rigid frame with a window of $127 \times 127 \mathrm{~mm}^{2}$; four rigid clamps with $5 \mathrm{~mm}$ radius; and a rigid impactor.

The impactor mass was adjusted to $4.98 \mathrm{~kg}$ (for $42 \mathrm{~J}$ impact energy) and to $11.94 \mathrm{~kg}$ (for $94 \mathrm{~J}$ ), for a constant impact velocity of $4 \mathrm{~m} / \mathrm{s}$, since large-mass/low-velocity impacts are governed by the impact energy [33]. The clamp contacts are ensured with a clamping force of $10 \mathrm{~N}$. The impactor and clamps are modeled as rigid surfaces associated to a reference node with mass. The frame is discretized with solid elements.

The laminate is discretized in plies ant interfaces. Each ply has one element through thickness: 8-noded solid elements with

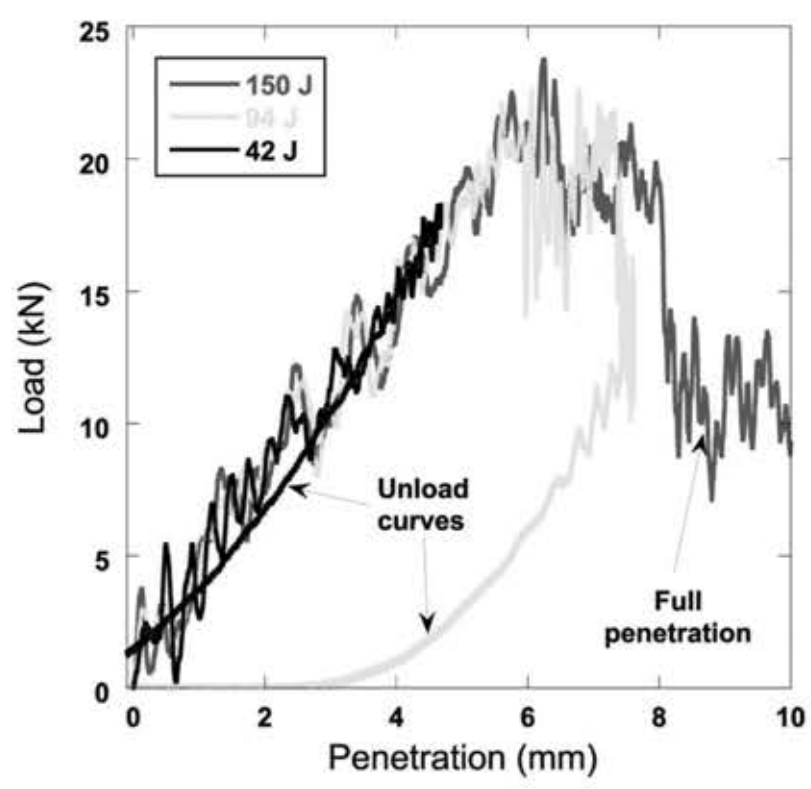

Fig. 3. Load-deflection curves of specimens tested under low-velocity impact. Impact energies of $94 \mathrm{~J}$ and $150 \mathrm{~J}$ showed partial or full penetration, respectively. The impactor rebounds at $42 \mathrm{~J}$.

reduced integration and "enhanced" hourglass control [34]. The minimum element size for each intralaminar failure mode is selected as the critical mesh size following equation (7). In this particular case, the failure mode that determines the in-plane element size is shear delamination. Two mesh densities are used (Fig. 4) due to computational limitations: a finer mesh around the impact zone with an element size of $0.5 \mathrm{~mm}$; and coarser mesh outside the impact zone with an element size of $1 \mathrm{~mm}$.

The model, consisting of approximately 2.5 million elements, was computed in a multi-processor computer cluster. The timestep is sensitive to the element distortion. To reach affordable computational time, three strategies are simultaneously used: element distortion control, element erosion and variable mass scaling. The first strategy introduces nodal forces proportional to the distortion, which do not significantly affect the constitutive response. The second removes the element when an elimination criterion is reached. The last strategy improves the timestep with an additional artificial mass. The total mass addition is always kept below $0.5 \%$. The viscous forces are kept within reasonable values (below 5\%) during the simulation.

\subsubsection{Contact and friction}

Contact between the impactor and the specimen is modeled by the General Contact Algorithm in Abaqus/Explicit which uses a penalty enforcement contact method [17]. This contact formulation is also applied between the different composite layers when the cohesive surfaces become fully damaged. Friction is introduced between all the contacting surfaces. The Coulomb friction model is used according to which the tangential motion between two surfaces is zero until the shear component of the surface traction reaches a critical value, $\tau_{\text {crit }}$, that depends on the normal contact pressure, $p$, and a friction coefficient, $\mu$, according to the relation $\tau_{\text {crit }}=\mu p$.

The friction coefficient between surfaces depends on the materials in contact and on the surface quality. Several authors have studied the subject of friction between metals and composite laminates and between delaminated surfaces [35-37]. In the last case, the friction coefficient is a function of the interface angle. For $0^{\circ} / 0^{\circ}$ interfaces it can be as low as 0.2 whilst for $90^{\circ} / 90^{\circ}$ interfaces it can 


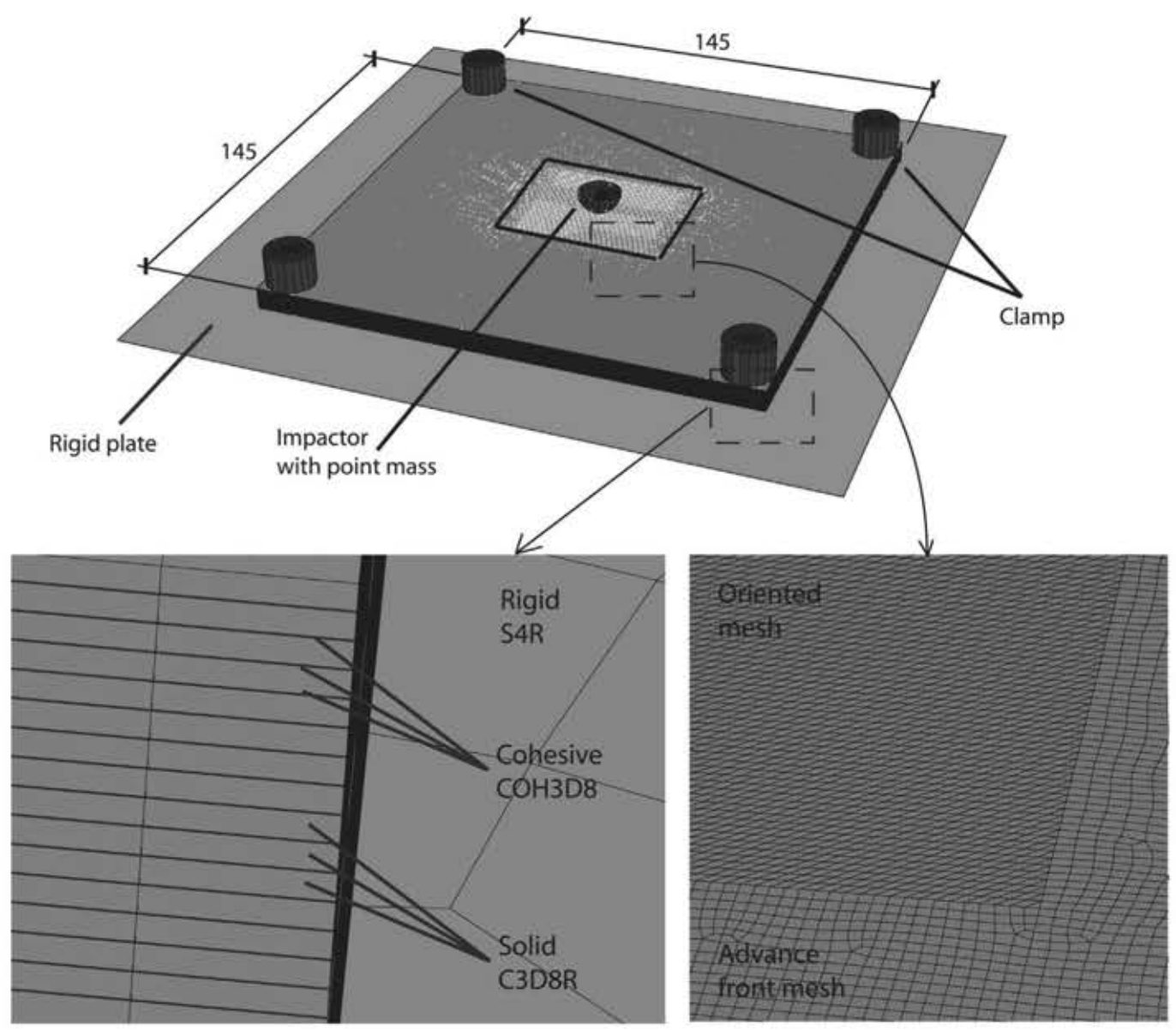

Fig. 4. FE model and mesh details of "improved intralaminar" model. Solid C3D8R elements in green, cohesive COH3D8 in red, rigid contact elements S4R in orange, analytical rigid surfaces in purple. Dimensions in $\mathrm{mm}$. (For interpretation of the references to color in this figure legend, the reader is referred to the web version of this article.)

be as high as 0.8 . In this work, an average friction coefficient of 0.5 is applied between ply surfaces independently of the interface angle. For metal-laminate contact (impactor-laminate and laminatesupports) a value of $\mu=0.3$ is used.

\subsection{Modeling strategies}

Four modeling strategies, involving different mesh structures and cohesive models, were considered:

\subsubsection{The baseline model}

The baseline model implements an unstructured mesh to prevent the development of preferential crack directions along mesh lines, as shown in Fig. 5a. The interply was modeled using conventional cohesive elements in Abaqus/Explicit [17]. An interface thickness of $0.01 \mathrm{~mm}$ was used with this strategy. The cohesive elements are eliminated when full damage is reached, and lamina-to-lamina contact was defined to avoid interpenetration. Similar modeling approaches for LVI on composite laminates can be found in Refs. [13-16].

\subsubsection{The base stable model}

The base stable model includes a similar strategy to the baseline model, but with an additional stabilization in the interply cohesive law: the delayed damage law [38]. In the delayed damage law, the cohesive equivalent opening is no longer calculated from the instantaneous displacement jump values, but is averaged with the previous values to avoid sharp non-physical changes in the opening value, effectively applying a low-pass filter of the form to the crack opening values. Here, the conventional cohesive elements are equipped with a user-defined material law through a subroutine VUMAT. The subroutine added a delayed damage law to the mixed-mode behavior used in the baseline model. The base stable model includes an additional parameter, the regularization parameter $\eta$, that converges to the previous approximation if $\eta=0$.

\subsubsection{The improved intralaminar model}

With respect to the baseline model, in the improved intra model the ply meshes are aligned with material directions. Contrary to the two previous models, the improved intralaminar model takes advantage of the fact that the macroscopic crack tends to align with the mesh [12]. A model with mesh alignment but with coincident nodes in adjacent plies was created (see Fig. 5). The nodal coincidence, but non-conformity of the element edges, is solved with a set of nodal cohesive springs [10]. In practice, the cohesive elements with Newton-Cotes integration of Abaqus/Explicit [17] are used. With this integration scheme, there is no force coupling between the degrees of freedom of different nodes, and the cohesive spring and the cohesive element approaches are equivalent.

\subsubsection{The improved intralaminar-interlaminar model}

In the improved intra-inter model the mesh alignment is combined with the use of cohesive contacting surfaces, instead of cohesive elements, to model interply delaminations. This method is easier to model and reduces the total number of elements. Additionally, the thickness of the cohesive interface is modeled as 


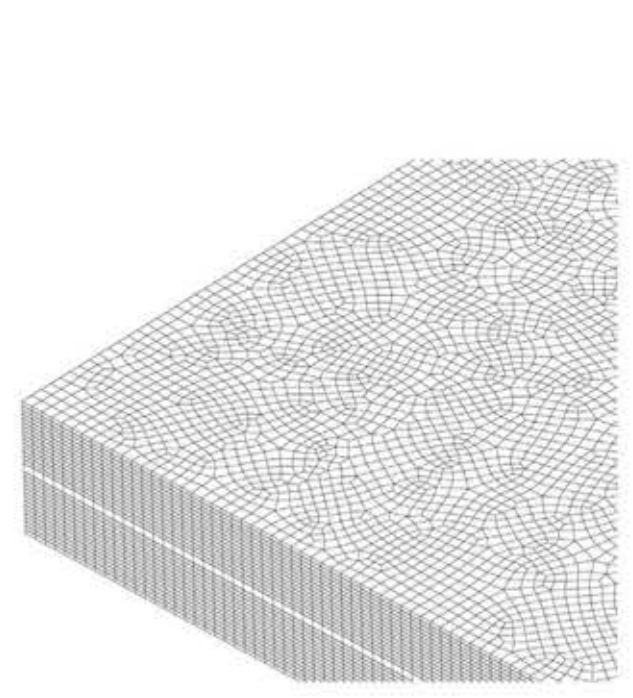

(a) Unstructured mesh

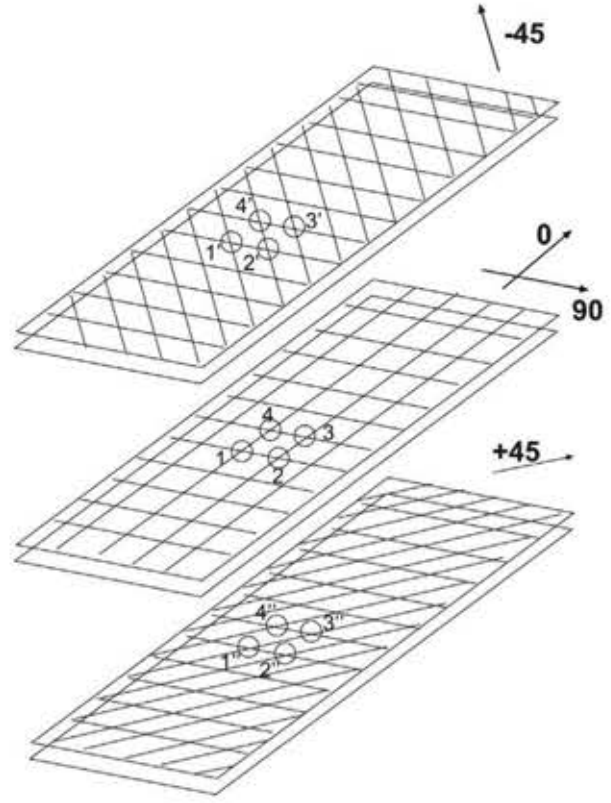

(b) Material-aligned mesh

Fig. 5. a) Unstructured mesh strategy: the mesh is extruded in the laminate thickness, b) Material-aligned mesh strategy: although the lamina meshes are not coincident, there is through-thickness nodal coincidence.

zero-thickness. However, the cohesive contact is more expensive in terms of computational cost per iteration.

\subsection{Virtual testing results}

The results of the baseline, base stable and improved intra models are compared in Fig. 6. The load curves are very similar in terms of the maximum load, laminate stiffness and load for the onset of delamination, with a higher degree of damping in the forcedisplacement curve of the base stable model. This damping is controlled by the damping parameter $\eta$.

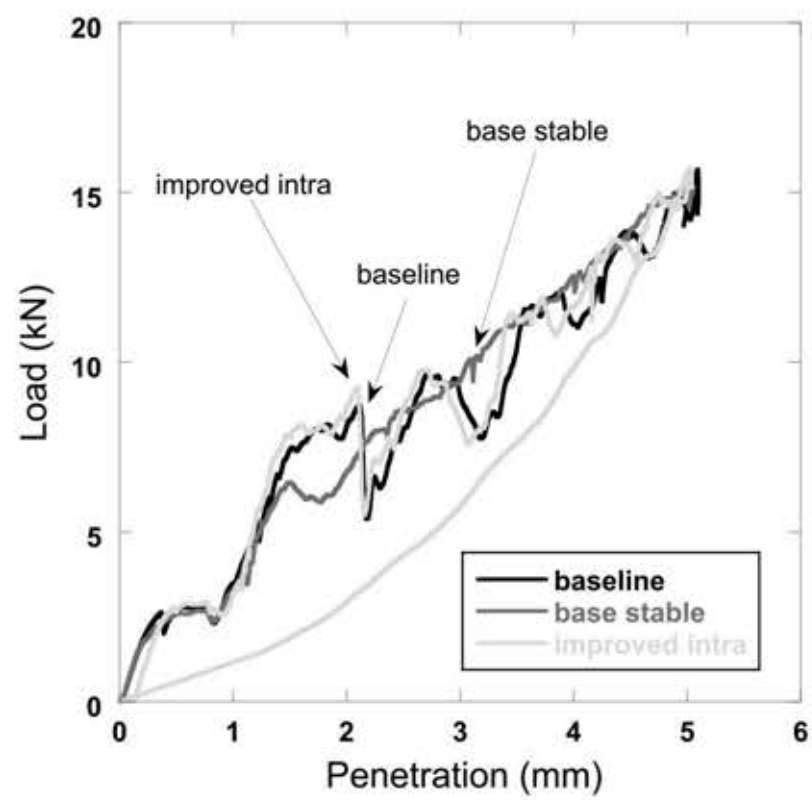

Fig. 6. Comparison of load-deflection curves for different modeling strategies. The onsets of delamination are marked with arrows.
The predicted load curves for the baseline and improved intrainter models are correlated with experimental data in Fig. 7. The quantities of interest for the comparison are the initial slope, the load at the onset of delamination, the maximum load supported by the laminate and the maximum delaminated area. The initial values of the curves are in very good agreement with the experiments, indicating that the elastic response of the system (laminate plies, indenter, initial contact areas, etc) is well captured by the model.

The onset of delamination corresponds to the first sudden load drop in the curves (Fig. 7) (ignoring the oscillations induced by dynamic effects). The onset of delamination in the baseline model is $9 \mathrm{kN}$ which compares with the experimental value of $12 \mathrm{kN}$. This is due to a different sequence of damage events in the simulation with respect to the experiments: the inspections suggest that the intralaminar crack propagates first, but delamination appears earlier in the simulation. The early failure turns to excessive delaminated area, as observed in Fig. 8, which is reflected on the loaddisplacement simulation curve offsetting from the experimental curve. Consequently, the maximum load is reduced from $18 \mathrm{kN}$ to $15 \mathrm{kN}$ for $42 \mathrm{~J}$. The base stable and the improved intra model give similar results.

The improved intra-inter model captures accurately the delamination onset at $12 \mathrm{kN}$. Probably, this is due to the geometric inconsistency, the finite thickness of the cohesive element, that does not appear in cohesive contact. The cohesive element does not interpolate the in-plane stress. As consequence, either the element thickness has to be zero or the out-of-plane stresses involved in the constitutive traction-separation law are overestimated due to the energy minimization principle. The consistency of the error is controlled by the element thickness, but due to practical considerations to maintain the stable timestep at acceptable values it is not recommended to further reduce it.

The ultrasonic C-scan damage evaluation data and the corresponding delamination predictions for the improved intra-inter model are compared in Fig. 8 for both impact energies under analysis. The C-Scan only determines the outer contour resulting of the 


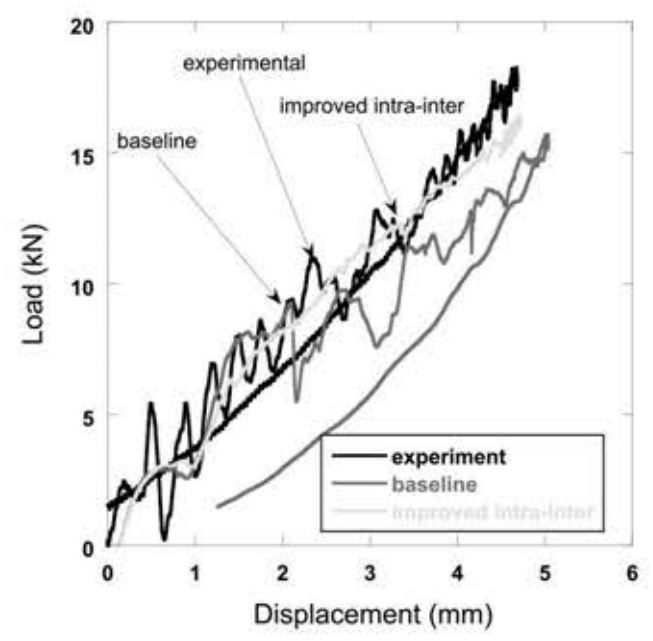

(a) $42 \mathrm{~J}$

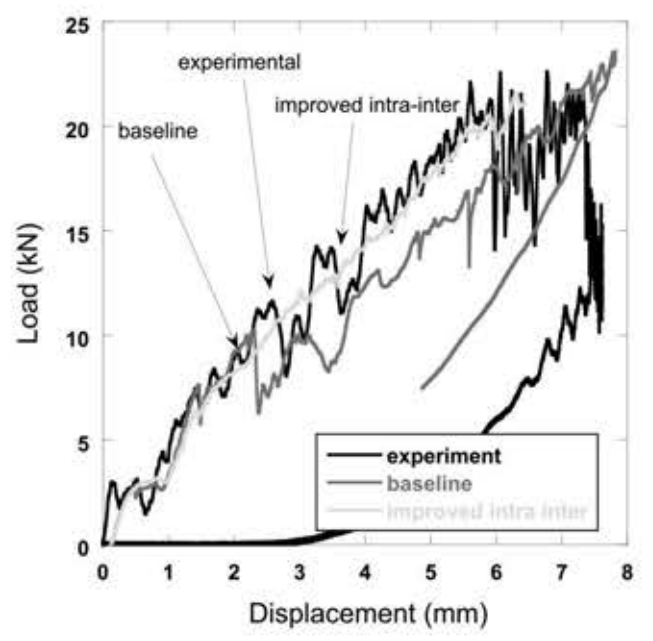

(b) $94 \mathrm{~J}$

Fig. 7. Comparison of experimental and simulation load curves for different modeling strategies. The onsets of delamination are marked with arrows.

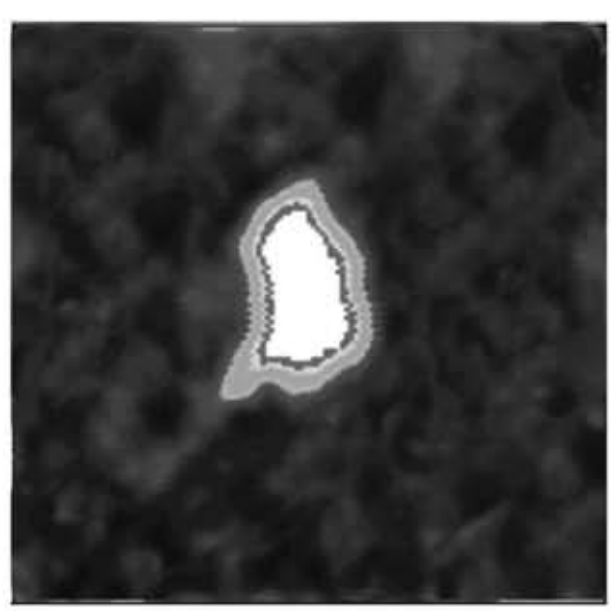

(a) 42J - C-scan

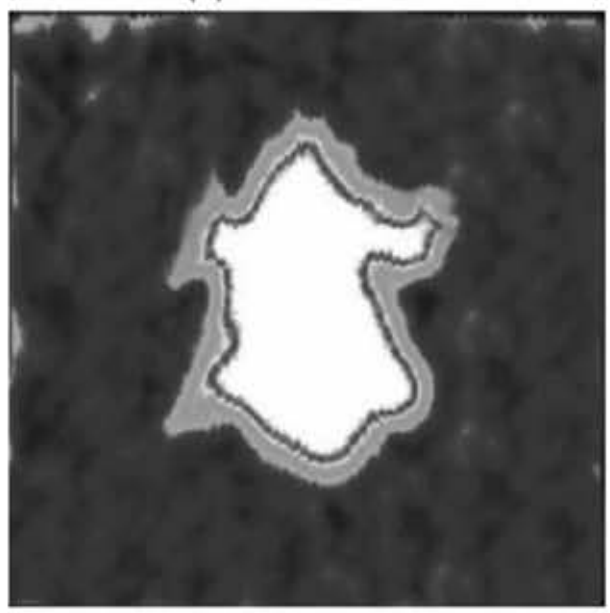

(c) $94 \mathrm{~J}$ - C-scan

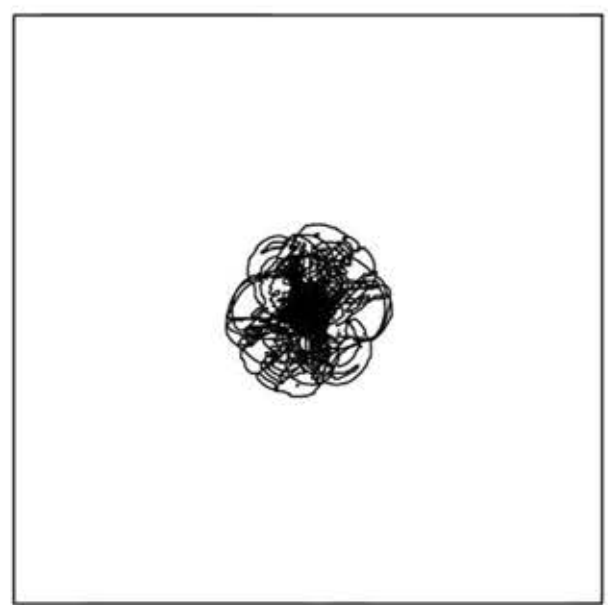

(b) $42 \mathrm{~J}$ - simulations

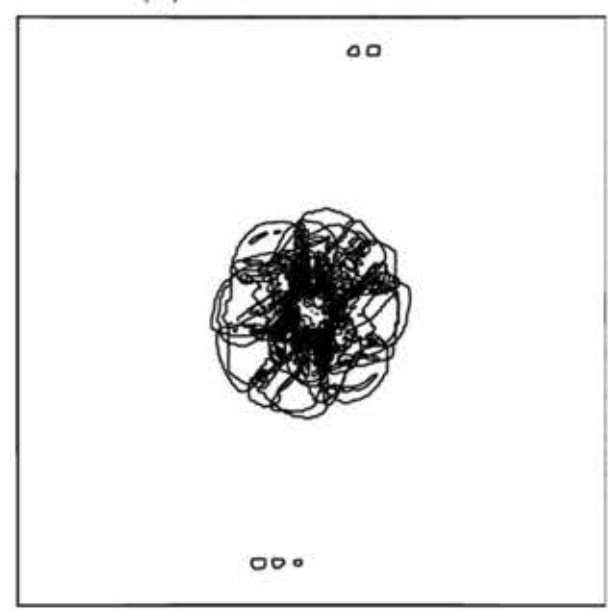

(d) $94 \mathrm{~J}$ - simulation.

Fig. 8. Correlation between experimentally-obtained delamination results and the ones predicted by the improved inter-intra model. 


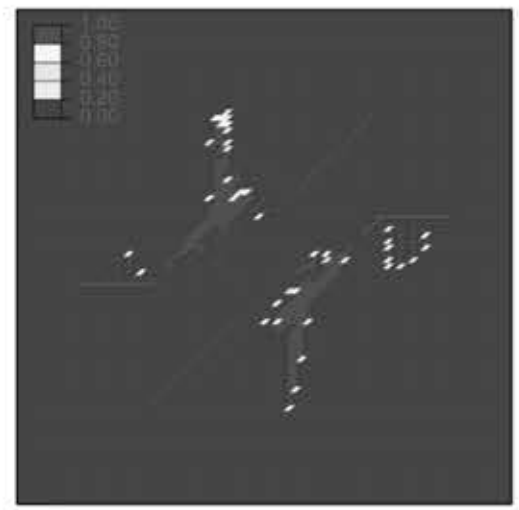

(a)

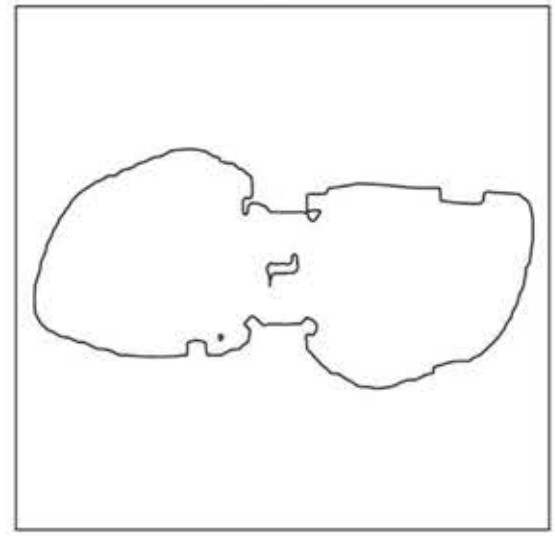

(c)

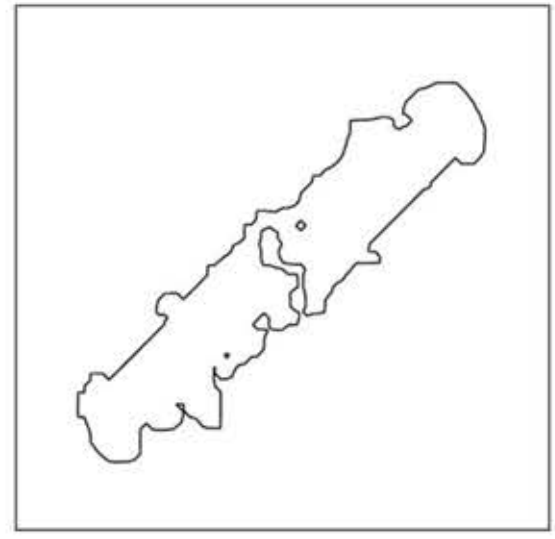

(e)

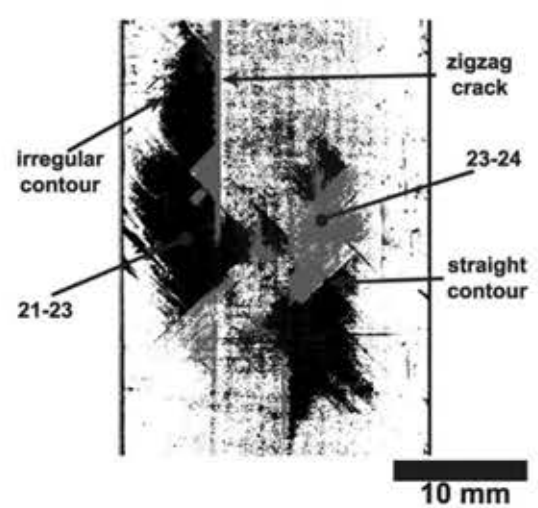

(b)

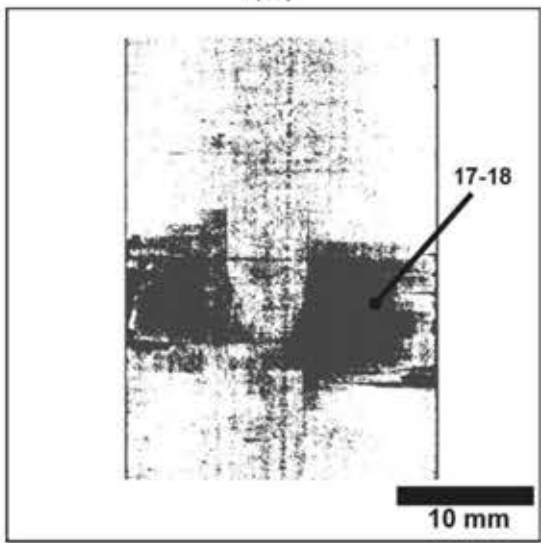

(d)

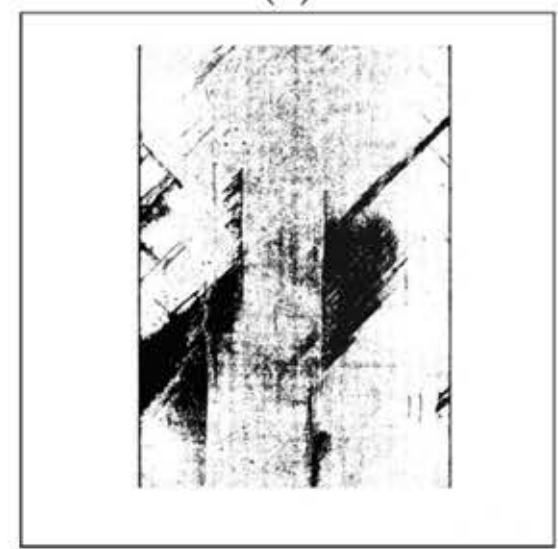

(f)

Fig. 9. Correlation between simulated (left) and experimentally-obtained (right) damage results for $42 \mathrm{~J}$ impact. a) and b) Matrix cracking in lamina 23 ( $+45^{\circ}$ ) (identified experimentally by the straight contours of the delaminations $21-23$ and 23-24). c) and d) Delamination pattern between laminas $17-18\left(0^{\circ} / 90^{\circ}\right)$. e) and f) Delamination pattern between laminas $13-14\left(+45^{\circ} / 90^{\circ}\right)$. Notes: plies are counted from the backface (non-impacted) of the specimen; the same scale is used in all figures.

superimposition of delaminations at different interfaces, while in the simulations the contour of each delamination is predicted. The delaminated area in the simulations has a more isotropic shape. The major explanation for this mismatch is that the typical fiber splitting of the back-face ply, that originates a large oblong delamination oriented along the ply angle, is not simulated by the models. In spite of that, the damage area measured by C-Scan evaluation is closely predicted.

Ply-by-ply and interface-by-interface damage results are correlated with corresponding X-ray tomography evaluations in Fig. 8.
The simulated intralaminar failure patterns resemble the ones obtained experimentally (Fig. $9 \mathrm{a}$ and b). For the plies stacked at $+45^{\circ}$ and $-45^{\circ}$ orientations, as well as for the other ones, the simulations tend to replicate matrix cracking patterns as observed in the experiments.

Fig. 9c-e shows highly anisotropic delaminations, that tend to propagate along the direction of the ply underneath (with respect to the impact face) and interact with intraply cracks in adjacent laminas. The delamination shapes are well captured in terms of qualitative shape but their area tends to be slightly overestimated. 


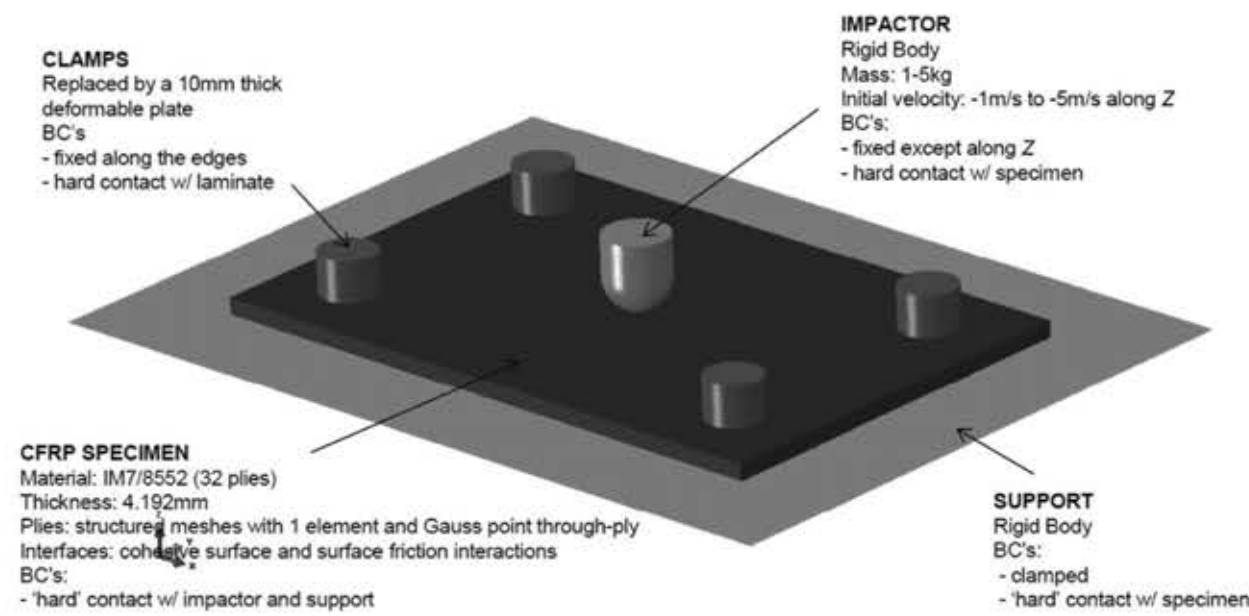

Fig. 10. Virtual setup for low velocity impact testing.

Overall, it can be concluded that the laminate response is well captured by the model. The drop test is strongly driven by the contact stresses at the impact point and by the initial damage print. The interply strength and fracture energies determine whether there is enough energy for the propagation of damage, and control its extension. The orthotropy of the composite plies tends to align the macroscopic intralaminar damage along the fiber directions. It is observed that two of the models, namely the baseline and improved intra models, provide results that are quite sensitive to perturbations. Probably, spurious high frequencies are affecting the simulation results. The bulk viscosity global control in Abaqus/ Explicit seems insufficient to control these oscillations, and improvements, such as adding viscosity to cohesive law in the base stable model, help making the results repeatable. The introduction of cohesive surfaces, in the improved intra-inter model, damps the oscillations significantly, due to the default numerical damping implemented in the contact algorithm. This is probably in closer resemblance to the reality where high-frequency oscillations are presumably avoided due to the polymer intrinsic damping properties.

\section{High-fidelity virtual LVI testing}

In this section, the standard test method for measuring the damage resistance of a fiber-reinforced polymer matrix composite to a drop-weight impact event [18], as devised by the American Society for Testing and Material (ASTM) is simulated using the most suitable modeling strategy identified in the previous section, namely the improved intra-inter model. These high-fidelity simulations are correlated with experimental results reported in Ref. [39].

\subsection{Modeling set-up}

Carbon/epoxy specimens fabricated by means of Automated Fiber Placement (AFP) and with the ply lay-up $\left[ \pm 45 / 90 / 0 / 45 / 0_{4} /-45 / 0_{2}\right]_{5}$ are simulated at different LVI energies. The $4.368 \mathrm{~mm}$ thick specimens consist of 24 unidirectional Hexply AS4/8552 plies with a nominal thickness of $h_{p}=0.182 \mathrm{~mm}$ each. The AS4/8552 ply properties used in this work are reported in Ref. [13]. Since some plies are clustered at $0^{\circ}$, the effective number of layers in the cured laminate is only 15 .

The FE models simulate similar geometry and boundary conditions as the ones indicated by the ASTM test standard (see Fig. 10) [18]. Composite test specimens of $150 \times 100 \times 4.368 \mathrm{~mm}^{3}$ are fixed between a steel support and a $10 \mathrm{~mm}$ thick steel plate which replaces four rubber clamps indicated by the ASTM standard, as in the experiments reported in Ref. [39]. The steel plate is itself bolted to the support along two lines of three bolts each, parallel to the longer specimen sides. Both plate and rigid support have a $125 \times 75 \mathrm{~mm}^{2}$ rectangular cut in the center leaving part of the specimens free for impact deflection. In the simulations, the support is considered perfectly rigid, fixed, and in contact with the specimen. The top plate, also in contact with the specimen and simplysupported along the bolt lines, is allowed to deform linearly. The modeled part of the steel plate measures $175 \times 150 \mathrm{~mm}^{2}$. The impactor is modeled as a rigid body with a lumped mass equal to the one used in the experiments. It has a spherically-shaped impact surface with a diameter of $16 \mathrm{~mm}$. An initial velocity in the vertical direction is prescribed to the impactor, simulating the impact velocity measured during the tests. Additionally, a force of magnitude $m_{i} g$ in the vertical direction is applied to the impactor to simulate the gravitational force, where $m_{i}$ is the impactor mass and $g$ is the acceleration due to gravity.

Similarly to the virtual test case described in Section 3, the composite specimen is discretized in two different zones kinematically tied together. In regions away from the impact, only the elastic behavior is simulated by means of a single layer of continuum shell elements that models the whole laminate. In the region around the impact each ply was modeled independently, each with one layer of solid elements with reduced integration, and mesh lines aligned with material orientations to guarantee that the direction of propagation of matrix cracking is parallel to the fibers. This creates nonconforming ply meshes through the thickness of the laminate, an issue which is easily dealt with by means of the ply-to-ply penalty contact algorithm coupled with cohesive surface behavior to simulate delamination by means of the traction-displacement laws previously described, and to prevent interpenetration of the delaminated surfaces. In order to prevent hour-glassing of the reduced integration elements, the enhanced strain method is used [34].

The mesh regularization is done, as previously described, by using the element characteristic length, $1^{*}$, as a variable $[4,5]$ (see Fig. 11). In non-aligned meshes, $I^{*}$ is a typical distance across the surface of the element which favors the use of squared-surface elements. In material-aligned meshes, two independent characteristic lengths, $l_{1+, 1-}^{*}$ and $l_{2+2-, 6}^{*}$ can be devised and used respectively with fiber and matrix dominated damage modes. In this section, $l_{1+, 1}^{*}=0.6 \mathrm{~mm}$ and $I_{2+, 2-6}^{*}=0,3 \mathrm{~mm}$.

Element erosion is used here to prevent high element distortions, which would render the element incapable of accurately computing the stress field, would lead to the reduction of the stable time increment in explicit integration, as explained above, and also 


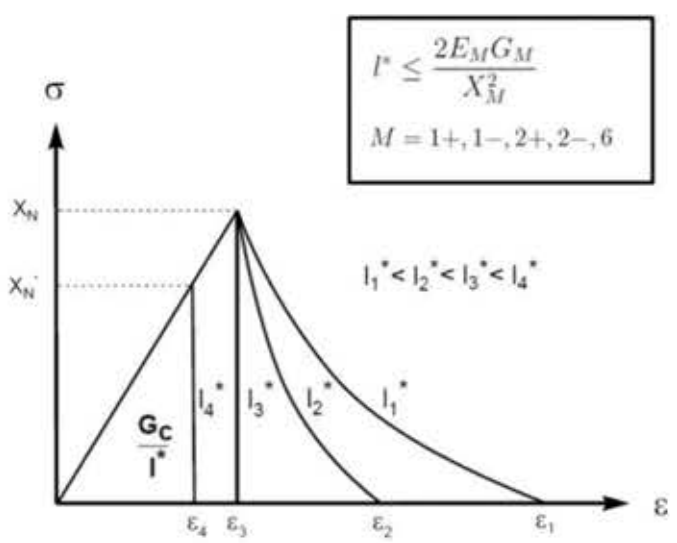

- Non-aligned mesh

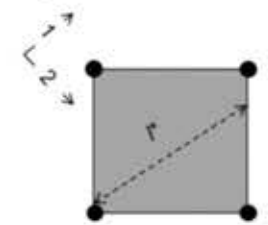

- Material-aligned mesh

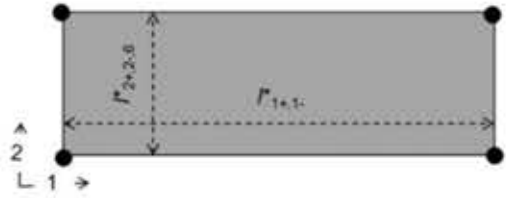

Fig. 11. Mesh regularization strategy.

to allow a good description of the kinematics of the impact process, from crack opening and fiber entanglement to specimen perforation. In the simulations explained herein, finite elements were eroded when the fiber damage variable, $d_{1}$, reached a value of 0.999 or the transverse tensile damage variable, $d_{2+}$, reached a value of 0.99 .

The FE meshes hold over one million elements in total. The amount of memory required by the analyses is over 10 Gbytes. Each run takes on average $48 \mathrm{~h}$ to complete using a cluster of four Intel Xeon IvyBridge $2.5 \mathrm{GHz}$ CPU's (10-core each). Such long calculation times are a direct result of the small stable time increment required by Abaqus/Explicit to handle elements of $0.6 \mathrm{~mm}$ by $0.3 \mathrm{~mm}$ in size. Mass scaling is applied to the model while keeping the total mass increase under $2 \%$.

\subsection{Simulation results}

Fig. 12depicts the simulated specimen deformations at maximum impactor penetration for four different impact energies (19.7 J, 29.7 J, $39.4 \mathrm{~J}$ and $50.8 \mathrm{~J}$ ). These energy levels correspond to laminate damage levels that range from below the Barely Visible Impact Damage (BVID)threshold, devised to be $26.4 \mathrm{~J}$ for this configuration [39], up to laminate perforation conditions. It is clearly seen that the damage
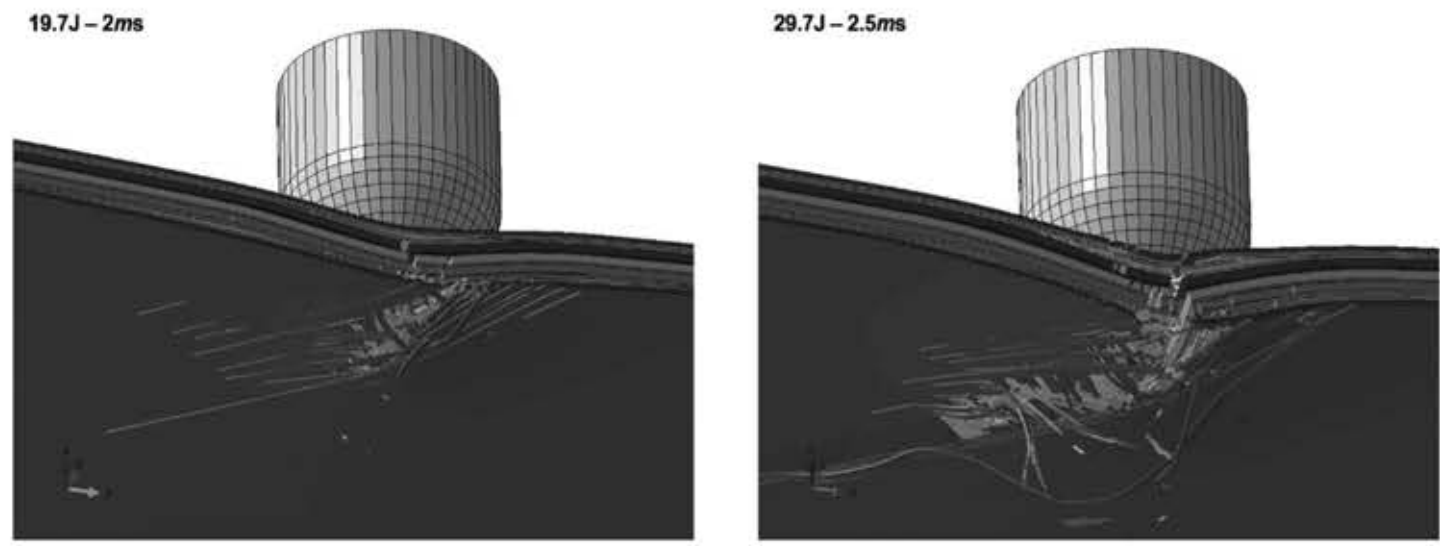

$39.4 \mathrm{~J}-2.6 \mathrm{~ms}$

$50.8 \mathrm{~J}-5.6 \mathrm{~ms}$
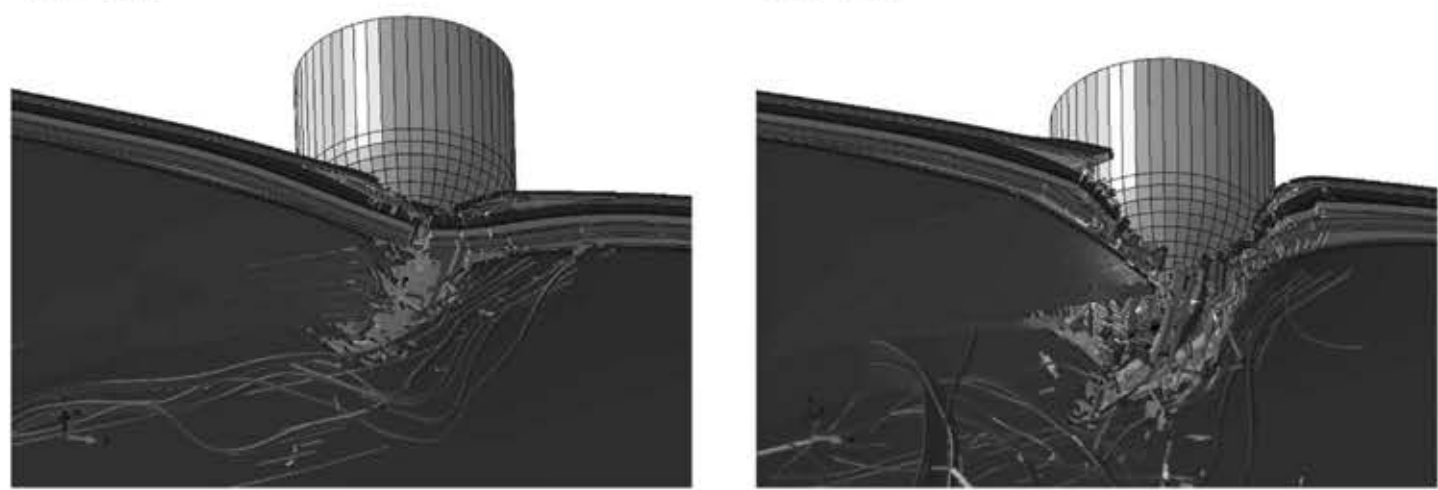

Fig. 12. Simulated specimen deformations at maximum impactor penetration for four impact energies. 

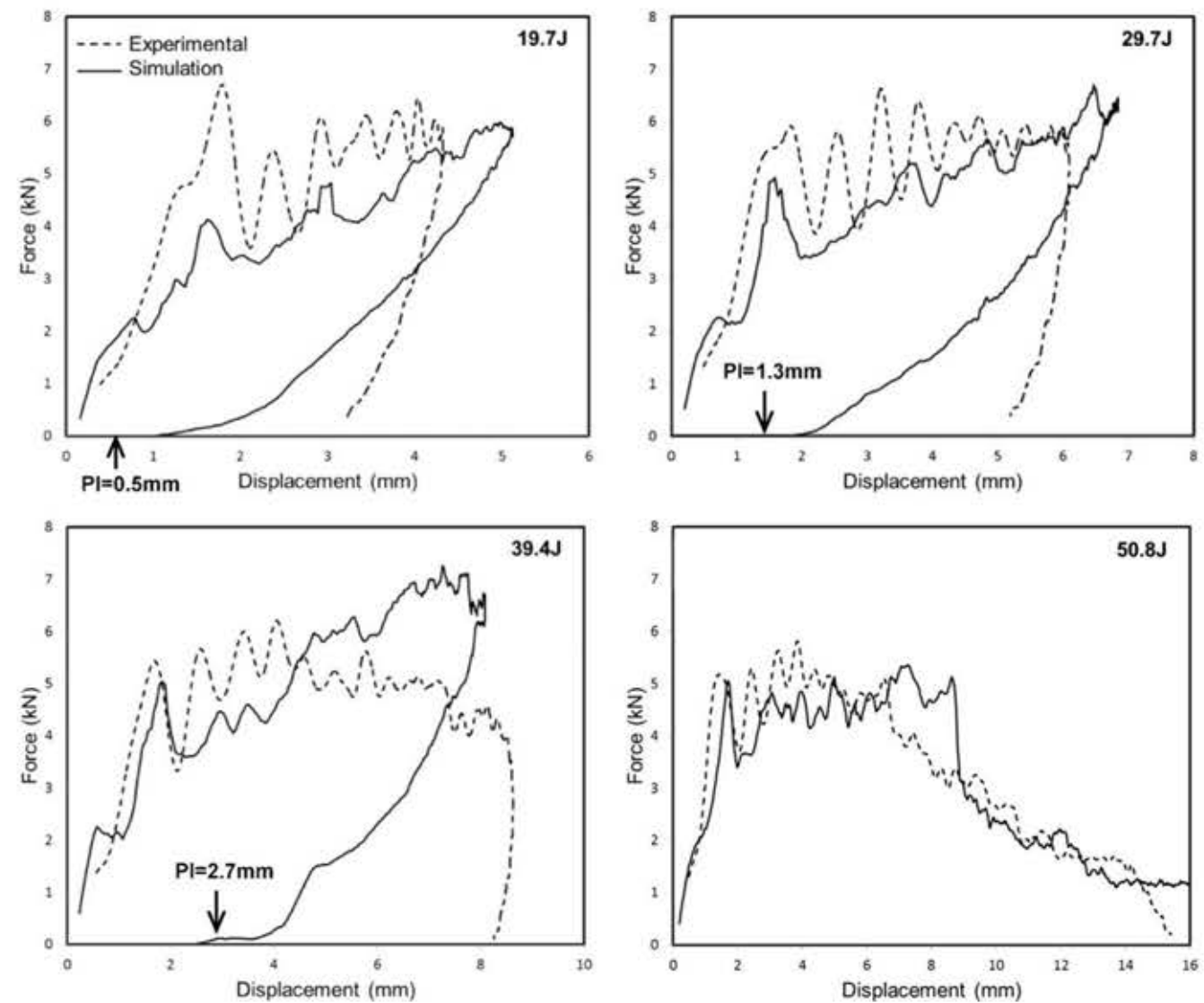

Fig. 13. Experimental and numerically simulated impactor reaction force vs, displacement for impacts at four different energies (PI = Permanent indentation - Experimental).

heavily increases with impact energy. Below BVID only blackface fiber splitting, due to the bending-induced transverse tension in the $45^{\circ}$ backface ply, is visible from outside the specimen, although matrix cracking and delaminations may have been generated on the inside. Above BVID the fiber splits extend towards the edges of the specimen and may even entirely separate from the laminate. At such energies, damage to the inner plies becomes visible even from the outside, both in the form of matrix cracks and of fiber breakage. At $50.8 \mathrm{~J}$ the impactor perforates the specimen. This can be con- cluded by the amount of specimen indentation and visible damage, as well as by the impactor displacement and by the impact time which largely increases from $39.4 \mathrm{~J}$ to $50.8 \mathrm{~J}$.

\subsubsection{Impact dynamics}

The load vs. displacement relations, obtained experimentally and by simulation, for the four impact energies are plotted in Fig. 13. The oscillatory behavior due to the dynamic coupling between the specimen and its metallic supports, observed in the experimental
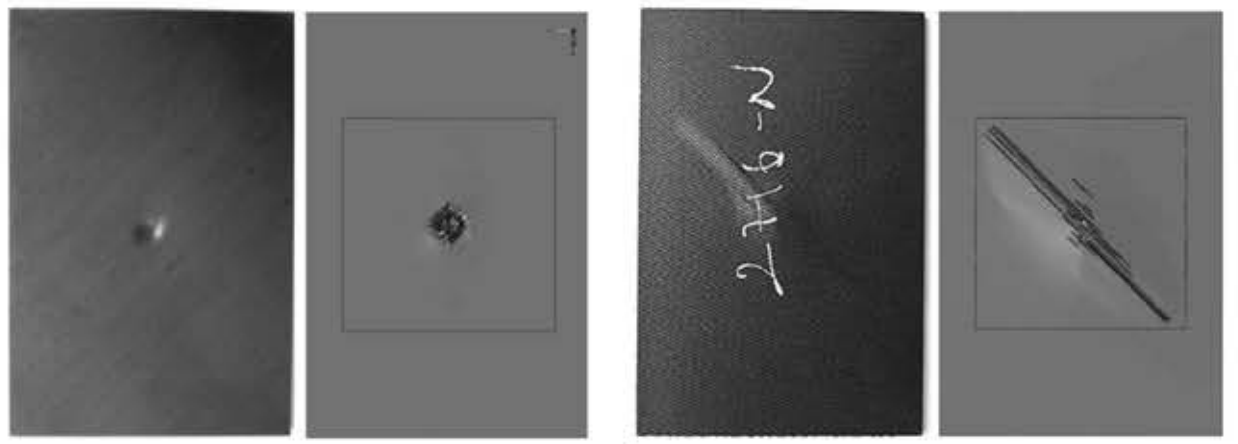

Permanent indentation $=1.6 \mathrm{~mm}$

Fig. 14. Experimental and simulated permanent indentation on the $29.7 \mathrm{~J}$ impact specimen due to intraply frictional effects and fiber entanglement. 
tests, is difficultly replicated by the explicit FE simulations which inevitably include unrealistic viscous dissipation mechanisms that damp the dynamic responses of the systems simulated [17]. However the general curve trends between experiments and the simulations correlate well. The elastic stiffness, the maximum impact force and the maximum impactor displacements of the specimens are generally well simulated by the numerical model for impact configurations ranging from below BVID to specimen perforation.

The predicted unloading curves differ from the ones achieved in testing. There is a permanent indentation on the specimens after the impact due to intraply frictional resistance, fiber entanglement, and matrix plastic behavior under shear loads. However, permanent indentation is not captured by the load-cell because there is evident loss of impactor-specimen contact and the force measured by the load cell reduces to zero before the composite specimen deflects back. The impact models take into account intraply frictional resistance and fiber entanglement. Furthermore, simulations are highly damped and there is less loss of contact between impactor and specimen before total spring-back. Therefore, the unloading curves tend to reflect better the permanent indentation values, as shown in Fig. 13. The permanent indentation on the composite specimen predicted by the simulation of the $29.7 \mathrm{~J}$ impact case is shown in Fig. 14. The predicted backface splitting is also shown, and is in good qualitative correlation with experimental results.

\subsubsection{Delamination}

The major delaminations in the composite specimen impacted at $29.7 \mathrm{~J}$ are shown in Fig. 15 for the purpose of comparing simulated and experimental results. The experimental technique employed to obtain the delaminated area at each interface is described in detail in Ref. [39]. The delaminations at interfaces $3 / 4\left(90^{\circ}\right)$ $0^{\circ}$ ) and $23 / 24\left(-45^{\circ} / 45^{\circ}\right)$ were not correctly identified by the experimental method (plies are counted from the backface towards the impact face). All other major delaminations are accurately predicted, in terms of size, shape and orientation. The expected delamination peanut shapes resulting from LVI on composite laminates are predicted at some interfaces, although these shapes were not accurately captured experimentally.

The predicted impact footprint is roughly the superimposition of delaminations at all interfaces since the other damage modes are normally concentrated on a narrower area. This information is compared, in Fig. 16, with the actual impact footprint obtained experimentally by ultrasonic C-scan [39]. Considering the limitations of the ultrasonic C-Scan technique, the simulated projected damaged area on each configuration agrees reasonably well with the experiments for all impact energies especially for the $19.7 \mathrm{~J}$ case. The models are relatively accurate in the identification of the blackface ply $\left(45^{\circ}\right)$ delamination triggered by face-ply matrix cracking and fiber splitting.

Both experimental and numerical results show that the impact footprint does not increase much for impact energies above $30 \mathrm{~J}$. This is because fiber breakage takes over delamination as the main damage mode, and the impactor actually starts to penetrate the specimen, as shown in Fig. 12, without further delamination increase.

\subsubsection{Matrix cracking and fiber breakage}

Matrix cracking appears to be the first damage phenomenon to occur in composite laminates undergoing impact loads, especially around the impact point. Above an impact energy threshold, which for the present configuration was determined to be somewhere between $5 \mathrm{~J}$ and $10 \mathrm{~J}$, matrix cracks propagate along with delamination. Above an even higher energy level, also fiber breakage plays a role in the damage process. These three damage modes are represented in Fig. 17, obtained by means of X-ray CT on the specimen impacted at $19.7 \mathrm{~J}$. The picture shows a planar section cut of the
Experimental

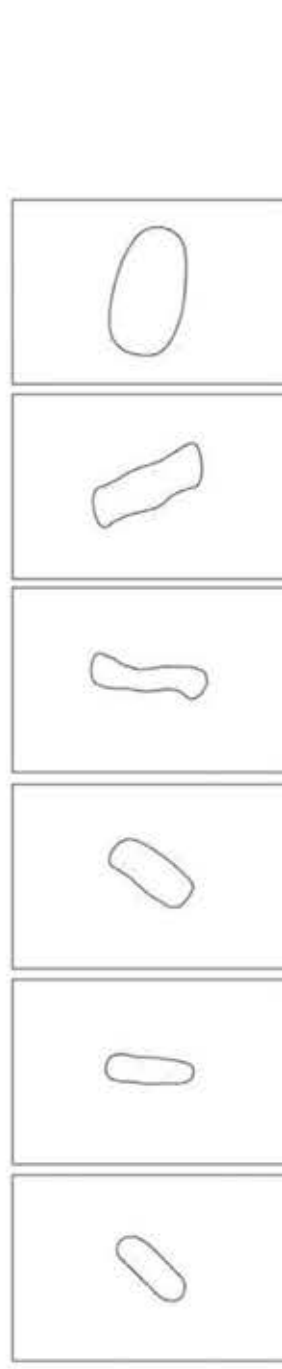

Simulation
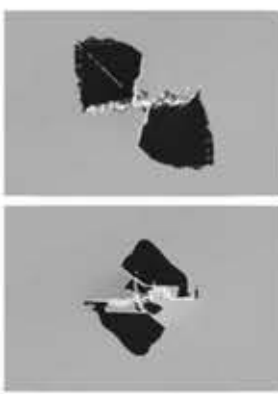

$21 / 22$

$0^{\circ} / 90^{\circ}$
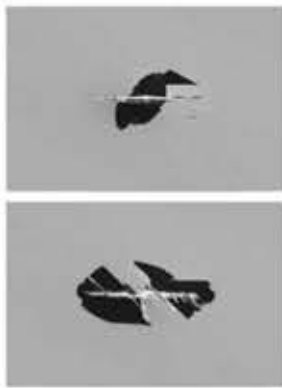

$15 / 16$

$-45 \% 0^{\circ}$

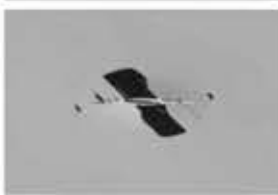

$14 / 15$

$0 \%-45^{\circ}$

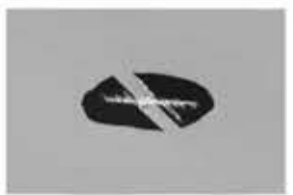

$10 / 11$

$-45 \% 0^{\circ}$

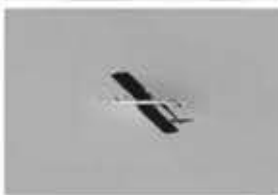

$9 / 10$

$0 \%-45^{\circ}$

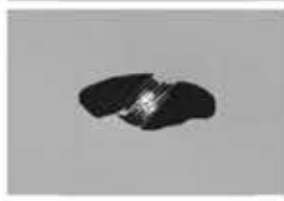

$3 / 4$

$90^{\circ} / 0^{\circ}$
Fig. 15. Major delaminations, by interface, for a 29.7 J impact. Experimental data (top) was obtained by carrying fluorescent penetrant inspection on the impact specimen. Each delamination is identified by the neighboring ply numbers and angles. Simulated matrix cracking and fiber breakage is represented in white. Plies are counted from the impact face of the specimen.

impacted specimen at about a depth of $3.6 \mathrm{~mm}$ away from the impact face. Due to the specimen indentation, parts of plies $19\left(0^{\circ}\right)$ and $20\left(45^{\circ}\right)$ are visible on the same picture as well as part of their interface. Although the comparison is not exactly fair, Fig. 17 also shows the simulation results on these two plies which correlate very well with the experimental results.

Both Figs. 15 and 17 show that matrix cracks are accurately predicted parallel to the fiber directions as observed experimentally. This is only possible because the mesh on each ply conforms to the ply orientation. The interaction between matrix and delamination is also well visible in those figures. In many plies delamination is seen to been driven or bounded by matrix cracks. In some plies, matrix crack make the delamination jump from one interface to another (e.g. $9 / 10$ to $10 / 11$, and $14 / 15$ to $15 / 16$ ). 
$19.7 \mathrm{~J}$

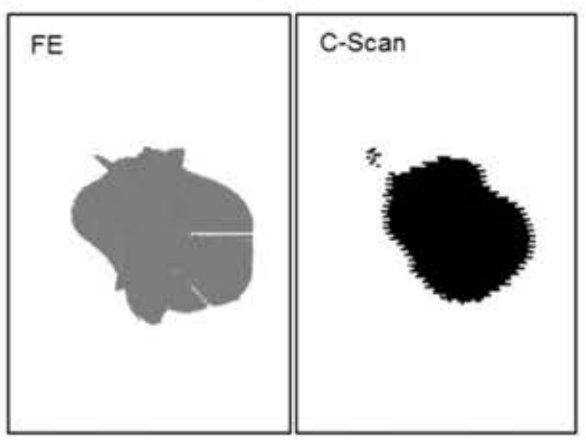

$39.4 \mathrm{~J}$

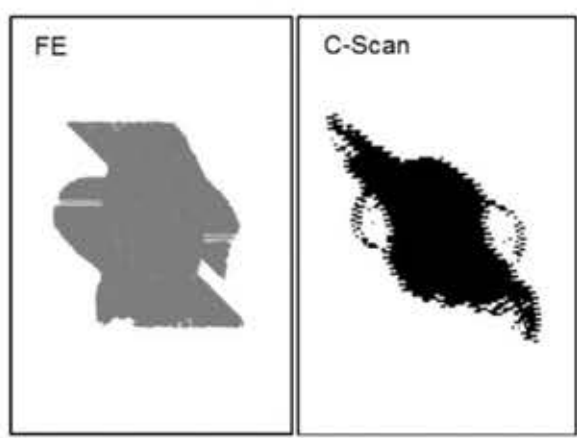

$29.7 \mathrm{~J}$

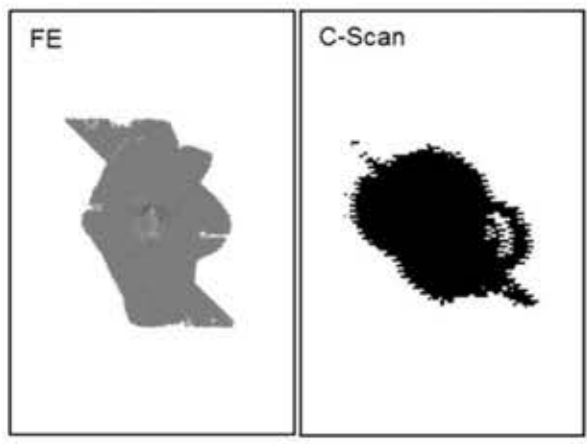

$50.8 \mathrm{~J}$

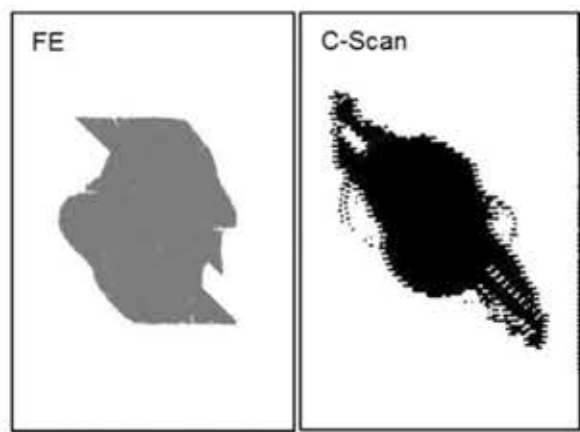

Fig. 16. Simulated impact footprints as compared with C-Scan results.

\section{Conclusions}

This work demonstrates the efficient prediction of the complex low-velocity impact response of composite laminates with remarkable accuracy by means of a mesoscale simulation strategy.

By using the explicit FE method, together with physicallybased constitutive damage models, which take into account the progressive failure behavior of fibers, matrix and interfaces between plies, the relevant physics of the impact process are correctly captured for impact configurations that range from below Barely Visible Impact Damage to specimen perforation. The use of ply-by-ply meshes, aligned with material directions, and ply-to-ply cohesive contact behavior allows the correct capturing of delamination, matrix cracking and fiber breakage at several impact energies and the reliable prediction of specimen perforation. The simulations are computationally expensive because of the large number of elements required and their small characteristic length which is associated with short stable time increments. The effort is rewarded with promising predictions of the impact duration, maximum impact force, maximum displacement, impact footprint, location and size of delaminations, as well as of matrix cracking and fiber damage.

Further work, specifically in the areas of modeling the nonlinear transverse shear and crushing behavior of composites and
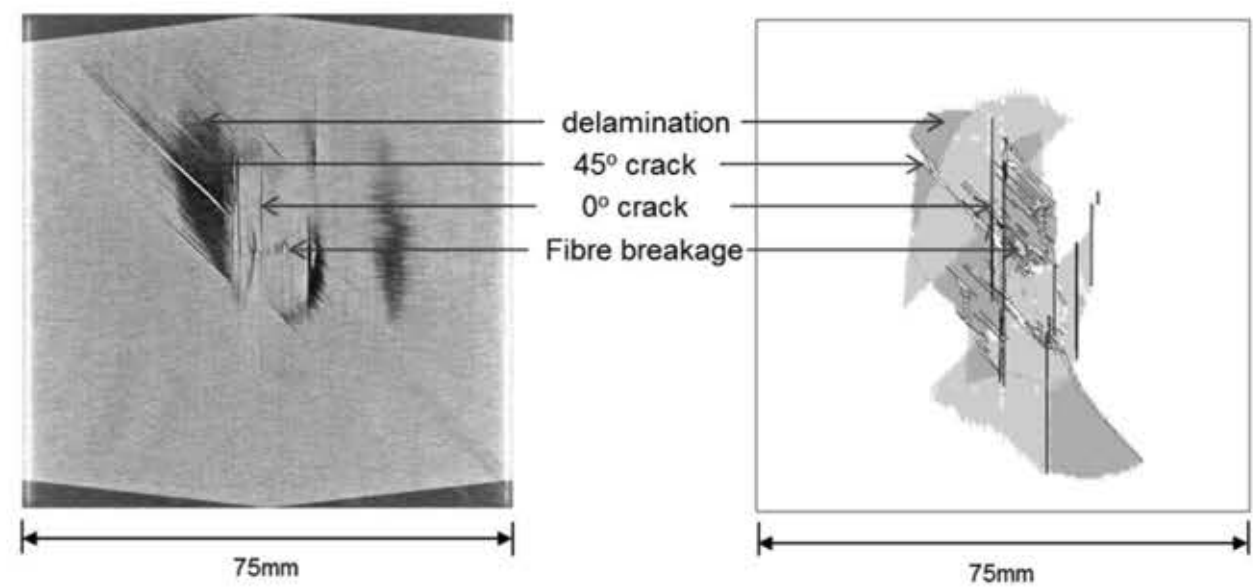

Fig. 17. X-ray tomography of the composite specimen impacted at $19.7 \mathrm{~J}$ as compared with simulation results. The X-ray tomography picture shows a planar section cut of the impacted specimen at about $3.6 \mathrm{~mm}$ away from the impact face. Parts of plies $19\left(0^{\circ}\right)$ and $20\left(45^{\circ}\right)$ are visible, and part of their interface. The simulation picture shows the full plies and respective interface. 
dependency of interlaminar fracture toughness on ply orientation is required to further enhance this modeling strategy.

\section{Acknowledgments}

The authors gratefully acknowledge the funding of this research by means of the project PTDC-EME-TME-111004-2009 from the Portuguese Foundation for Science and Technology (FCT) and by means of the grant agreement 213371 from the European Community FP7 Programme (MAAXIMUS, http://www.maximus.eu).

\section{References}

Abrate S. Impact on composite structures. Cambridge, England: Cambridge University Press; 1998.

Reid SR, Zhou G. Impact behaviour of fibre-reinforced composite materials and structures. Cambridge, England: Woodhead Publishing Limited: 2000.

Sleight DW. Progressive failure analysis methodology for laminated composite structures, Tech. rep. Hampton, VA: NASA, Langley Research Center: March 1999, NASA/TP-1999-209107.

Maimí P, Camanho PP, Mayugo JA, Dávila CG. A continuum damage model for composite laminates - part i: constitutive model. Mech Mater 2007:39:897-908. Maimí P. Camanho PP, Mayugo JA, Dávila CG. A continuum damage model for composite laminates - part ii: computational implementation and validation. Mech Mater 2007;39:909-19.

Pinho ST, Dávila CG, Camanho PP lannucci L Robinson P. Failure models and criteria for FRP under in-plane or three-dimensional stress states including shear non-linearityTech, rep.., . Hampton, VA: NASA, Langley Research Center; February 2005, NASA/TM-2005-213530.

Camanho PP, Dávila CG, Pinho S, lannucci L, Robinson P. Prediction of in situ strengths and matrix cracking in composites under transverse tension and in-plane shear. Compos A Appl Sci Manuf 2006:37:165-76.

Bažant Z, Oh B. Crack band theory for fracture of concrete. Mater Struct 1983:16:155-77.

Bažant ZP. Jirásek M. Nonlocal integral formulations of plasticity and damage: survey of progress. J Eng Mech 2002;128(11):1119-49.

Bouvet C, Rivallant S, Barrau J-J. Low velocity impact modeling in composite laminates capturing permanent indentation. Compos Sci Technol 2012: 72(16): 1977-88.

Dang T, Hallett SR, Kim BC, Cahain YL, Butler R, Liu W. Modelling of as manufactured geometry for prediction of impact and compression after impact behaviour of variable angle tow laminates. J Compos Mater 2014:48:1-16.

Laš V. Zemčik R. Progressive damage of unidirectional composite panels. J Compos Mater 2008;42(1):25-44.

Lopes CS, Camanho PP, Gürdal Z, Maimí P, González EV. Impact behaviour of dispersed stacking sequence laminates. Part II: numerical simulations. Compos Sci Technol 2009:69:937-47.

Lopes CS. Damage and failure of non-conventional composite laminates [Ph.D. thesis]. . The Netherlands: Delft University of Technology: June 2009.

González EV, Maimí P, Camanho PP, Turon A, Mayugo ]. Simulation of dropweight impact and compression after impact tests on composite laminates. Compos Struct 2012:94:3364-78.

Feng D, Aymerich F. Finite element modelling of damage induced by lowvelocity impact on composite laminates. Compos Struct 2014:108:161-71.

Abaqus, Inc. Abaqus version 6.13 user's manual. 2013. Providence, RI, USA

Standard test method for measuring the damage resistance of a fibre-reinforced polymer matrix composite to a drop-weight impact event, Tech. rep. West
Conshohocken, PA, USA: American Society for Testing and Materials (ASTM); 2005, ASTM D 7136/D 7136M-05.

González E, Maimi P. Turon A, Camanho PP, Renart ]. Simulation of delamination by means of cohesive elements using an explicit finite element code. Comp Mater Continua 2008:9:51-92.

Camanho PP, Davila CG. Mixed-mode decohesion finite elements for the simulation of delamination in composite materials, Tech. rep. Hampton, VA: NASA, Langley Research Center: June 2002, NASA/TM-2002-211737.

Camanho PP, Maimi P. Dávila CG. Prediction of size effects in notched laminates using continuum damage mechanics. Compos Sci Technol 2007:67:2715-27. Standard test method for tensile properties of polymer matrix composite materials, Tech. rep. West Conshohocken, PA, USA: American Society for Testing and Materials (ASTM): 2000, ASTM D 3039/D 3039M-00.

Standard test method for compressive properties of unidirectional or cross-ply fibre-resin composites, Tech, rep. West Conshohocken, PA, USA: American Society for Testing and Materials (ASTM): 1987, ASTM D 3410-87.

Standard test method for in-plane shear response of polymer matrix composite materials by test of a $\pm 45^{\circ}$ laminate, Tech. rep. West Conshohocken, PA, USA: American Society for Testing and Materials (ASTM); 1994, ASTM D3518/3518M94.

LLorca J, González C, Molina-Aldareguia JM, Segurado J, Seltzer R, Sket F, et al. Multiscale modeling of composite materials: a roadmap towards virtual testing. Adv Mater 2011:23(44):5130-47.

LLorca J, González C, Molina-Aldareguía J, Lópes C. Multiscale modeling of composites: toward virtual testing. ... and beyond. JOM 2013:65(2):215-25. Standard test methods for mode 1 interlaminar fracture toughness of unidirectional fibre-reinforced polymer matrix composites, Tech, rep. West Conshohocken, PA, USA: American Society for Testing and Materials (ASTM); 2001. ASTM D 5528-01.

Pinho ST, Robinson P. lannucci L. Fracture toughness of the tensile and compressive fibre failure modes in laminated composites. Compos Sci Technol 2006:66(13):2069-79.

Catalanotti G, Xavier J, Camanho PP. Measurement of the compressive crack resistance curve of composites using the size effect law. Compos A Appl Sci Manuf 2014:56:300-7.

Catalanotti G, Arteiro A, Hayati M, Camanho PP. Determination of the mode crack resistance curve of polymer composites using the size-effect law. Eng Fract Mech 2014;118:49-65.

Martin R, Elms T, Bowron S. Characterization of mode II delamination using the 4ENF, In: Proceedings of the 4th European conference on composites; testing and standardisation, Lisbon, Portugal. 1998.

Crews JH, Reeder JR. A mixed-mode bending apparatus for delamination testing, Tech. rep. Hampton, VA: NASA, Langley Research Center: 1988, NASA/TM100662.

González E, Maimí P. Camanho P, Lopes C, Blanco N. Effects of ply clustering in laminated composite plates under low-velocity impact loading. Compos Sci Technol 2011:71(6):805-17.

Puso MA. A highly efficient enhanced assumed strain physically stabilized hexahedral element. Int J Numer Methods Eng 2000;49(8):1029-64.

Sung N, Suh N. Effect of fiber orientation on friction and wear of fiber reinforced polymeric composites. Wear 1979:53:129-41.

Schön J. Coefficient of friction of composite delamination surfaces. Wear 2000:237:77-89.

Bing $Q$, Sun CT. Effect of transverse normal stress on mode II fracture toughness in fiber composites. In: 16 th International conference on composite materials, Kyoto, Japan. 2007.

Allix O, Feissel P, Thévenet P. A delay damage mesomodel of laminates under dynamic loading: basic aspects and identification issues. Comput Struct 2003:81(12):1177-91.

Lopes CS, Seresta O, Gürdal Z, Camanho PP. Thuis B. Impact behaviour of dispersed stacking sequence laminates. Part I: Experiments. Compos Sci Technol 2009:69:926-36. 